\title{
Spatial and Temporal Characteristics of Meteorological Drought in Shandong Province, China, from 1961 to 2008
}

\author{
Xiaoli Wang, ${ }^{1,2}$ Xiyong Hou, ${ }^{1} \mathrm{Zhi} \mathrm{Li}^{3}$ and Yuandong Wang ${ }^{1,2}$ \\ ${ }^{1}$ Yantai Institute of Coastal Zone Research, Chinese Academy of Sciences, Yantai 264003, China \\ ${ }^{2}$ University of Chinese Academy of Sciences, Beijing 100049, China \\ ${ }^{3}$ College of Natural Resources and Environment, Northwest A\&F University, Yangling, Shaanxi 712100, China \\ Correspondence should be addressed to Xiyong Hou; xyhou@yic.ac.cn
}

Received 10 February 2014; Revised 20 April 2014; Accepted 5 May 2014; Published 15 June 2014

Academic Editor: Shengli Huang

Copyright (C) 2014 Xiaoli Wang et al. This is an open access article distributed under the Creative Commons Attribution License, which permits unrestricted use, distribution, and reproduction in any medium, provided the original work is properly cited.

\begin{abstract}
Shandong province is located in the northern part of China and tends to be a drought-prone region. This study is dedicated to making a comprehensive and quantitative analysis of the spatial patterns of drought frequency and its climate trend coefficient, drought grades, and temporal characteristics of drought coverage area, drought duration, and drought intensity from 1961 to 2008 by using the meteorological drought composite index (CI). The results indicated that the occurrence frequency of meteorological drought in Shandong province was generally high and some part of this region such as Jiaodong peninsula had suffered drought pressure with an evident ascending trend. The drought extent and influence were very severe in 1980s and 1990s but very slight in 1964; large-area drought mainly occurred after the 1970s and the yearly and seasonally interdecadal drought duration both showed a fluctuation of 10a periodic cycle approximately. Furthermore, the slight drought mainly appeared in the northwest and southwest while the other grades of drought exhibited much significant spatial and temporal variability. Besides, drought in spring was more serious than that in winter. This study is anticipated to support the mitigation of drought hazards and to improve the management practices of environment system in Shandong province.
\end{abstract}

\section{Introduction}

According to the Intergovernmental Panel on Climate Change (IPCC) report [1], the land surface temperatures have risen globally over the past century and a half, which have shown significant regional variations also. And global warming intensifies the global hydrological cycle in terms of the averaged precipitation, evaporation, and runoff; thus it further compounds the drought occurrence around the world [2]. In particular in recent decades, drought occurred frequently, and large-scale intensive drought has been observed in many continents, such as Africa [3, 4], Asia [5, 6], Europe $[7,8]$, and America $[9,10]$. Being located in East Asia, China has been suffering large-scale and long-lasting severe droughts since the early 1950s, which had negative impacts on environment, ecosystem, social-economic development, and people's living conditions [11, 12]. For example, the frequent occurrence of severe droughts in 1997, 1999, and 2002 in
Shandong province, Hebei province, Gansu province, Inner Mongolia Autonomous Region, and so on had caused very serious economic and societal losses [13]. In 1997, the very severe drought in northern China resulted in a period of 226 days with no streamflow in the Yellow River, which is the longest drying-up duration on record [2]. Thus it is of great importance to carry on more thorough drought research at local and regional as well as national scales, especially to those areas with insufficient water resources. However, due to the complexity of drought dynamics and its diverse influencing factors such as temperature, relative humidity, high winds, monsoons, rains, and latitudes, the accurate monitoring and comprehensive evaluating of drought are still a big challenge.

The American Meteorological Society classifies drought into four categories, including meteorological, hydrological, agricultural, and socioeconomic drought [14]. The meteorological drought, which is mainly used for monitoring and assessing the water deficit degree aroused by climate 
anomalies in a region within a certain period of time, is the fundamental reason for the occurrence of other droughts. Therefore, it contributes to further researches of other types of drought to explore the meteorological drought's causes and laws and to carry out effective monitoring, early warning, and historical assessment of meteorological drought hazards. As a primary method for assessing the effect of drought, the drought index is a numerical expression of drought parameters, such as intensity, severity, duration, and spatial extent. Many indices have been developed so far to quantify a drought among which some meteorological drought indices have been implemented widely at present, such as the standardized precipitation index (SPI) [15-17], Palmer drought severity index (PDSI) $[18,19]$, and vegetation condition index (VCI) $[20,21]$. Recently, the meteorological drought composite index (CI), which was proposed by China Meteorological Administration, has been used in many regions in China. Compared to meteorological indices previously reported such as SPI and PDSI as well as VCI, CI has the advantage of taking water-heat balance into consideration for drought stress characterization because it combines both precipitation and temperature information; it has the ability to identify the drought onset and termination, severity, and duration as well as drought-hit area; therefore it is suitable for real-time meteorological drought monitoring and assessment of the historical meteorological drought [22]. For instance, Zhao et al. [23] made a prediction of meteorological drought risk with CI in Yunnan province, supporting the quantitative analysis of drought influencing factors such as LUCC in this region. Based on the calculation of CI, Zou et al. [24] studied the drought areas variations for ten major Chinese river basins and China as a whole from 1951 to 2008, revealing the drought areas trends and pointing out the significant drought areas in China. What is more, by employing CI, several other meteorological drought researches had been taken out in eastern [25] and northwest [26] and some other regions in China.

In this study, we made a thorough and quantitative analysis of the spatial-temporal dynamics of the meteorological drought that occurred in Shandong province from 1961 to 2008 by adopting CI which has not been employed in this region. Specifically, we analyzed the spatial patterns of drought frequency and its climate trend coefficient, drought grades, and temporal characteristics of drought coverage area, drought duration, and drought intensity in the expectation of providing reasonable reference and scientific support for alleviating and mitigating the impacts of meteorological drought.

\section{Study Area and Data}

2.1. Study Area. Shandong province is situated in the downstream area of the Yellow River; it lies between E $114^{\circ} 36^{\prime} \sim \mathrm{E}$ $122^{\circ} 43^{\prime}$ and $\mathrm{N} 34^{\circ} 25^{\prime} \sim \mathrm{N} 38^{\circ} 23^{\prime}$, respectively. Being located in the eastern coast area of China, Bohai Sea borders its north and Yellow Sea borders its northeast and southeast (Figure 1). Being affected by the typical warm temperature monsoon climate, Shandong province is characterized by cold and less rain in spring, being hot and rainy in summer, moderate precipitation and temperature in autumn, and being cold and dry in winter, respectively. The average annual temperature is $11 \sim 14^{\circ} \mathrm{C}$, increasing form northeast to southwest. The average annual precipitation is generally between 550 and $950 \mathrm{~mm}$, decreasing from southeast to northwest. The seasonal distribution of rainfall is uneven because nearly $60 \sim 70 \%$ precipitation concentrate in summer, tending to induce or form floods. However, there are so less rainfall in autumn, winter and spring, and the droughts arouses easily in these seasons. Furthermore, with a large population and widespread farmland but limited water resources, Shandong province is facing severe water scarcity due to an increasing demand of water resource by population's livelihood, agriculture, energy, and industry sectors. Therefore, Shandong province becomes a drought-prone region, which threats regional social-economic development and living standard of local dwellers. However, as for researches that have been reported on drought hazards in Shandong province, it mainly focused on drought causes from the aspect of climatology background in terms of atmospheric circulation and monsoon [27], or drought characters by assessing statistical data such as temperature, precipitation, and disaster losses $[28,29]$; there is a shortage of quantitative exploration of meteorological drought from the perspective of spatialtemporal characteristics $[30,31]$ and different severity levels with a long time series in this region.

2.2. Meteorological Data. The meteorological data records with excellent quality through a strict quality control were selected from the Chinese Terrestrial Climate Information of Daily Datasets. There are 32 representative meteorological stations in these datasets in Shandong province; however, due to the limitation of inconsistency observation records in some stations, we finally choose 18 meteorological stations' daily climate data including measured average temperature and precipitation data from 1961 to 2008 . In order to satisfy the requirements of CI calculation, the meteorological records in nearly 50 years were readily preprocessed according to the data processing document.

\section{Methodology}

3.1. Meteorological Drought Composite Index. In this study, CI was employed to analyze the spatial and temporal characteristics of meteorological drought in Shandong province at time scales of seasonal and interannual. CI is calculated based on standardized precipitation index (SPI) and relative moisture index (MI) as follows [22]:

$$
\mathrm{CI}=a Z_{30}+b Z_{90}+c M_{30}
$$

where $Z_{30}$ and $Z_{90}$ refer to the SPI of 30 days and 90 days, respectively, $M_{30}$ represents the MI of 30 days, and $a, b$, and $c$ are coefficients.

SPI was developed for the purpose of defining and assessing drought by McKee et al. [15], and it was computed following Zhang et al. [22] in this paper. MI indicates the 


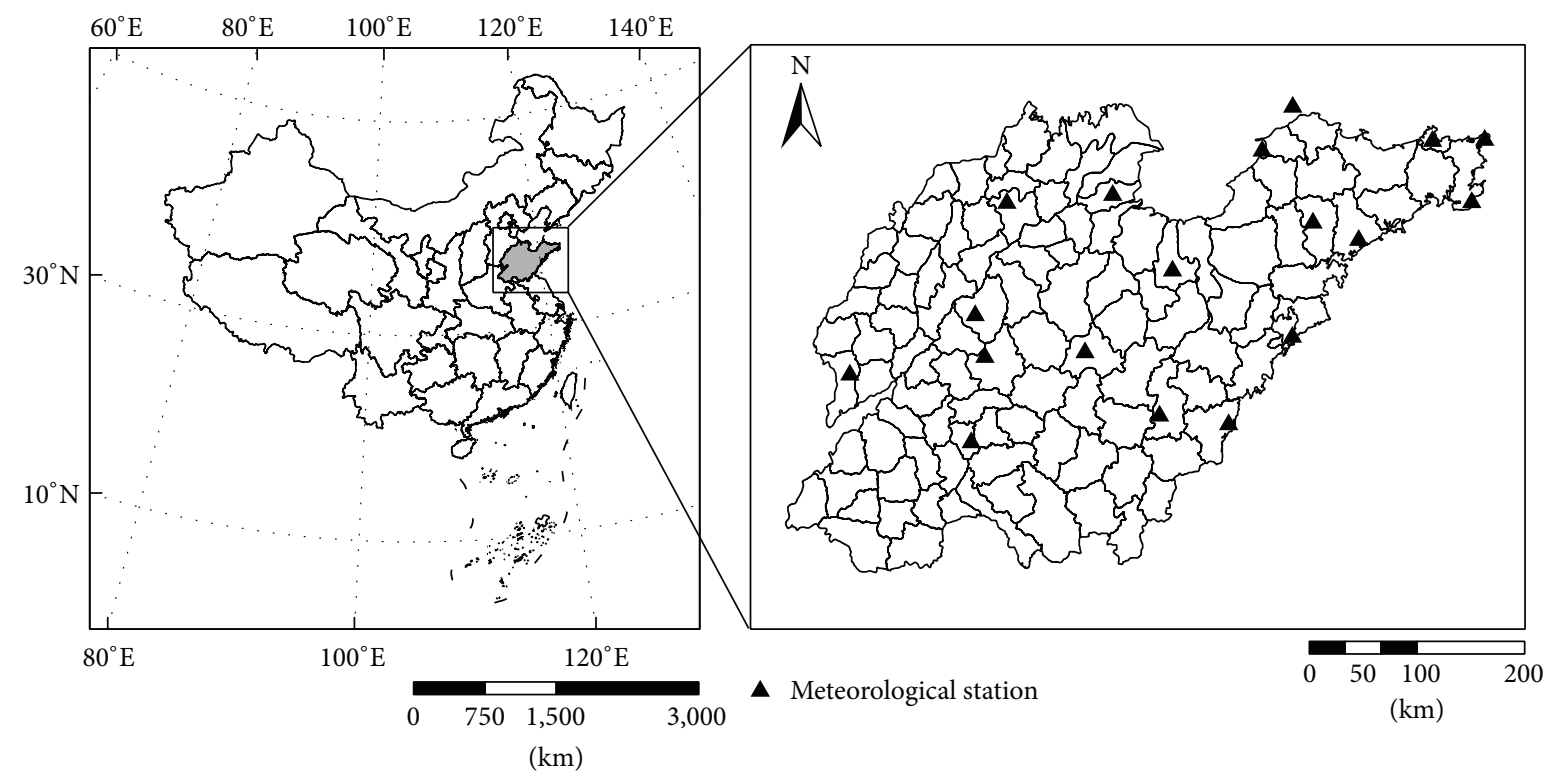

FIGURE 1: Location map of Shandong province and the meteorological stations.

balance between precipitation and evaporation during a period of time, and it was calculated as follows:

$$
\mathrm{MI}=\frac{P-\mathrm{PE}_{m}}{\mathrm{PE}_{m}},
$$

where $P$ refers to the total amount of precipitation in the recent 30 days (unit: $\mathrm{mm}$ ) and $\mathrm{PE}_{m}$ is the potential evapotranspiration in the recent 30 days (unit: $\mathrm{mm}$ ). The potential evapotranspiration was calculated based on the Thornthwaite function according to Zhang et al. [22].

The meteorological data including the daily average temperature and daily precipitation were employed to calculate the CI according to formula (1), and the CI was classified based on Table 1 [23].

3.2. Determination of the Meteorological Drought Process. We adopted CI to determine the meteorological drought process. A meteorological drought process is initiated when $\mathrm{CI}$ in 10 consecutive days is above slight drought level $\left(\mathrm{CI}_{10} \leq-0.6\right)$, and this process is terminated until another 10 consecutive nondrought days appear $\left(\mathrm{CI}_{10}>-0.6\right)$. The drought duration refers to the period between the first date and last date of the whole process. A drought event for a specific time scale (month, season, and year) appears when there is at least one occurrence of a drought process and the length of cumulative drought duration exceeds a quarter of the timescale [22]. In addition, the drought intensity is referred to the sum of all CI values above slight drought level during a drought process in which smaller values indicate stronger drought intensity.

In this paper, the annual and seasonal drought duration in Shandong province were obtained by calculating the arithmetic mean of the total number of days of all drought processes for total meteorological stations within the corresponding periods. And the annual drought intensity was defined as the arithmetic mean of the drought intensity for
TABLE 1: Classification standard of the meteorological drought composite index (CI).

\begin{tabular}{lcc}
\hline Level & Class & CI \\
\hline 1 & No drought & $-0.6<\mathrm{CI}$ \\
2 & Slight drought & $-1.2<\mathrm{CI} \leq-0.6$ \\
3 & Moderate drought & $-1.8<\mathrm{CI} \leq-1.2$ \\
4 & Heavy drought & $-2.4<\mathrm{CI} \leq-1.8$ \\
5 & Extreme drought & $\mathrm{CI} \leq-2.4$ \\
\hline
\end{tabular}

total meteorological stations for each year. The definition of season is as follows: winter covers January, February, and December of last year, spring is from March to May, summer is from June to August, and autumn covers from September to November.

3.3. Drought Frequency and Its Climate Trend Coefficient. The drought frequency is calculated as follows:

$$
F=\frac{n}{N} \times 100 \%
$$

where $F$ is the drought frequency, $n$ refers to the number of drought years, and $N$ represents the total number of years. In this paper, there were 48 years from 1961 to 2008 ; thus $N$ took the value of 47 because $\mathrm{CI}$ was calculated by rolling back.

The climate trend coefficient is used to describe the temporal characteristics of climate trend change intensity quantitatively [32]; it is calculated as follows:

$$
r_{x t}=\frac{\sum_{i=1}^{n}\left(x_{i}-\bar{x}\right)(i-\bar{t})}{\sqrt{\sum_{i=1}^{n}\left(x_{i}-\bar{x}\right)^{2} \sum_{i=1}^{n}(i-\bar{t})^{2}}},
$$

where $r_{x t}$ refers to the correlation coefficient between factor sequence and natural sequence in $n$ years, $x_{i}$ is the factor value in the $i$ year, $\bar{x}$ represents the sample mean, and $\bar{t}=(n+1) / 2$. 
In this study, the climate trend coefficient of drought frequency was calculated based on the occurrence frequency of drought in five decades for each meteorological station at time scales of year and season. The positive and negative values of $r_{x t}$ reflect linear increase and decrease trends of drought frequency in $n$ years, respectively. And the spatial distribution of drought frequency and its climate trend coefficient as well as different drought grades were obtained by employing the inverse distance weighting (IDW) interpolation method in ArcGIS 9.3 platform.

3.4. Drought Coverage Area. The probability of drought coverage area (PDCA) is defined as the area ratio of drought events that occur for a given timescale in the study region and is calculated as follows:

$$
S=\frac{m}{M} \times 100 \%
$$

where $S$ is the probability of drought coverage area, $m$ is the number of meteorological stations in which drought events that occur for a given timescale, and $M$ refers to the total meteorological stations. The PDCA of more than $90 \%$ is defined as the large-area drought in this research [25].

\section{Spatial-Temporal Characteristics of Meteorological Drought}

4.1. Spatial Patterns of Drought Frequency and Its Climate Trend Coefficient. There are very significant spatial differences of meteorological drought frequency from 1962 to 2008 in Shandong province. It can be seen that the annual drought frequency decreased both from north to south and from west to east (Figure 2(a)). The annual high drought frequency mainly concentrated in the north and southwest Shandong province, with a maximum percentage of more than $80 \%$. In contrast, low frequency centered in the central and southeastern Shandong province as well as the eastern Jiaodong peninsula, with the lowest occurrence in Taishan about $53.9 \%$. Drought frequency at four seasons also showed very distinct spatial differences. In spring it varied from $63.83 \%$ to $80.85 \%$, which is the highest among four seasons, and high values mainly located in northwest and southwest (Figure 2(b)). The scopes of drought frequency in summer (Figure 2(c)) and autumn (Figure 2(d)) were 42.55\% 72.34\% and $51.06 \% \sim 74.47 \%$, respectively, exhibiting a similar spatial pattern that the minimum frequency occurred in Taishan and southeast areas and the maximum frequency appeared in north and southwest regions. In winter, the drought frequency varied from $36.17 \%$ to $74.46 \%$, which was lower than any other seasons, and low value areas spread widely, including almost the entire central area and most parts of northern area (Figure 2(e)). Overall, the southwest and north areas were prone to high drought frequency, but the central and southeast regions were susceptible of relative low drought frequency.

Furthermore, the temporal trend analysis of drought frequency showed that the meteorological drought in Shandong province tended to be aggravating from 1962 to 2008
(Figure 3(a)). The spatial distribution of drought frequency tendency in spring (Figure 3(b)) was similar to that in autumn (Figure 3(d)) and winter (Figure 3(e)), presenting an ascent trend in eastern and northern area of Shandong province, especially in Jiaodong peninsula. In summer, the increasing trend of drought frequency was observed in finite areas, around Weifang city and Jiaodong peninsula mainly (Figure $3(\mathrm{c})$ ). In general, it demonstrates that regions of significant aggravating drought during 1962 to 2008 mainly concentrated in the northern and southern part and Jiaodong peninsula, showing a certain degree of meteorological drought aggravation, and need to be focused on for mitigating the drought stresses in the future.

4.2. Spatial Patterns of Different Drought Grades. The spatial patterns of different drought grades from 1962 to 2008 in Shandong province are shown in Figure 4. In the respect of annual drought, over the past nearly 50 years, the number of slight drought, moderate drought, and severe and extreme drought days that occurred in Shandong province were between 57 81d (Figure 4(a)), 32 49d (Figure 4(b)), and $11 \sim 23 \mathrm{~d}$ (Figure 4(c)), respectively. Spatially, the days of slight drought decreased from west to east, and the days of moderate drought showed a zonal distribution, with south being more than north, which was conversely with the pattern of severe and extreme drought. Overall, the distributions of high-value centers for every drought grade have no common features whereas low-value centers were all in the Taishan area.

In spring, the annual days of slight drought, moderate drought and severe and extreme drought were 16 25d (Figure 4(d)), 11 16d (Figure 4(e)), and 4 9d (Figure 4(f)), respectively. And the high value centers of slight drought were located in the western and northern regions, with drought days exceeding more than $22 \mathrm{~d}$; on the contrary, the Taishan area and Weihai-Shidao in Jiaodong peninsula were not prone to slight drought. The moderate drought was mostly observed in the west to Weifang-Juxian areas. Moreover, the severe and extreme drought was the most severity in four seasons, exhibiting a high-value in the eastern part of Jiaodong peninsula and low-value in the Taishan area.

In summer, the annual days of slight drought, moderate drought, and severe and extreme drought were 10 17 d (Figure 4(g)), 5 11 d (Figure 4(h)), and 3 7d (Figure 4(i)), respectively. And the high incidence areas for each drought grades mainly located in the north, northwest, southwest, and the Jiaodong peninsula; whereas the low incidence areas were all in and around the Taishan area.

In autumn, the annual days for the three drought grades were 14 22d (Figure 4(j)), 9 15d (Figure 4(k)), and 3 $6 \mathrm{~d}$ (Figure 4(1)), respectively. The slight drought was likely to occur in the northwest, southwest, and the east area of Jiaodong peninsula. And the moderate drought days were $11 \sim 13 \mathrm{~d}$ in most areas of the province, except the Yellow River delta and Rizhao city (high-value centers of moderate drought) and Taishan area (low-value center of moderate drought). In addition, the northwest and southwest were vulnerable to severe and extreme drought in autumn, with drought days more than $4 \mathrm{~d}$. 


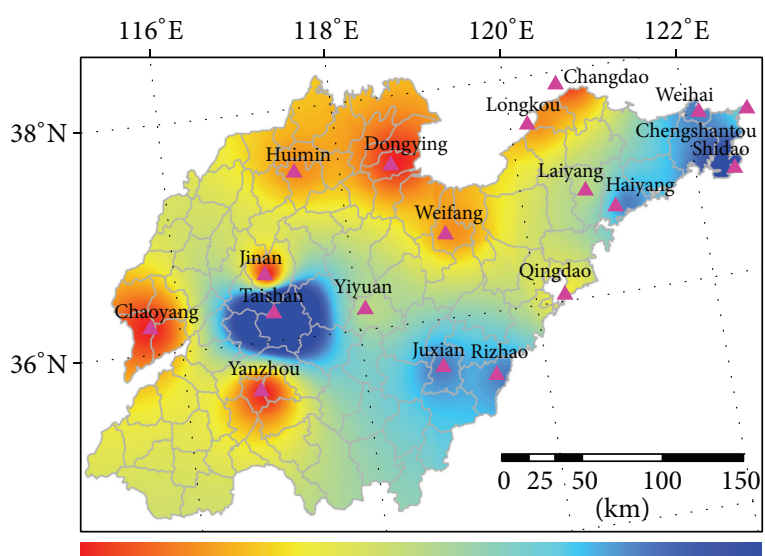

High: 82.98

- Meteorological station

(a)

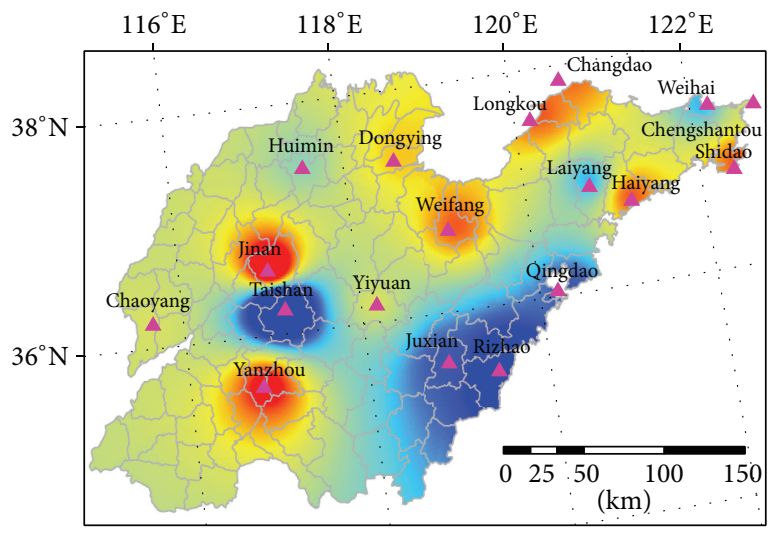

High: 72.34

Drought frequency $(\%)$

- Meteorological station

(c)

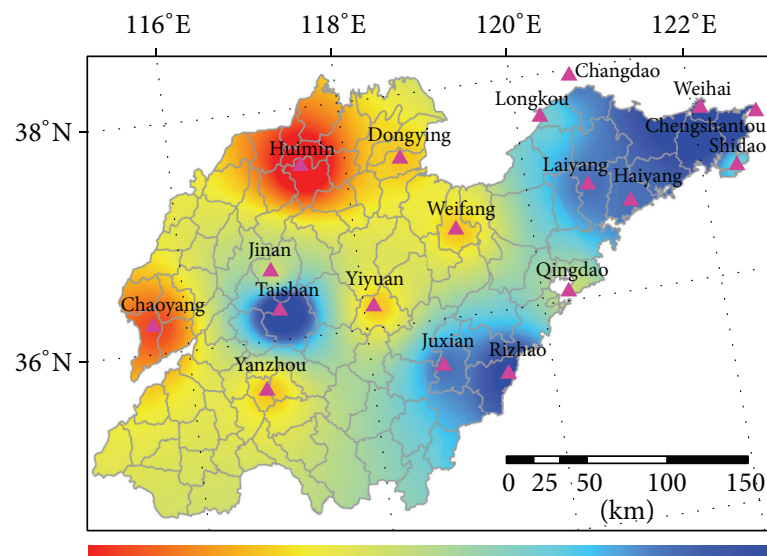

High: 80.85

Drought frequency (\%)

- Meteorological station

(b)

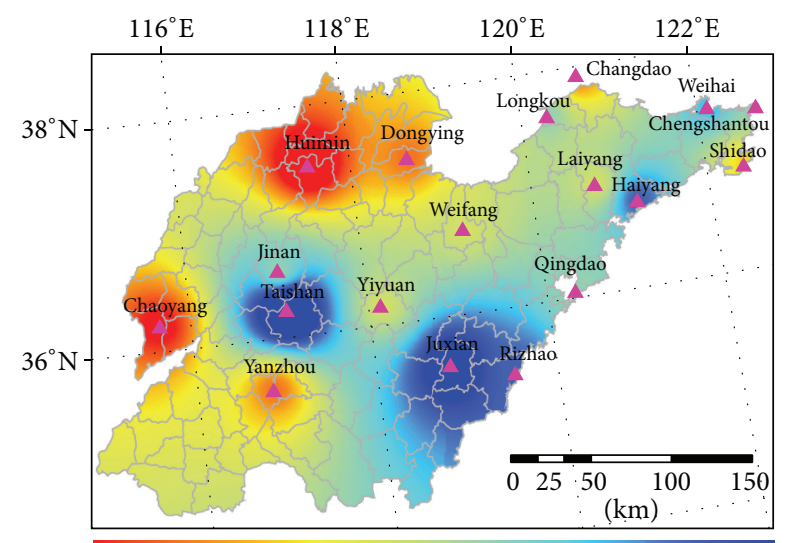

High: 74.47

Drought frequency $(\%)$

- Meteorological station

(d)
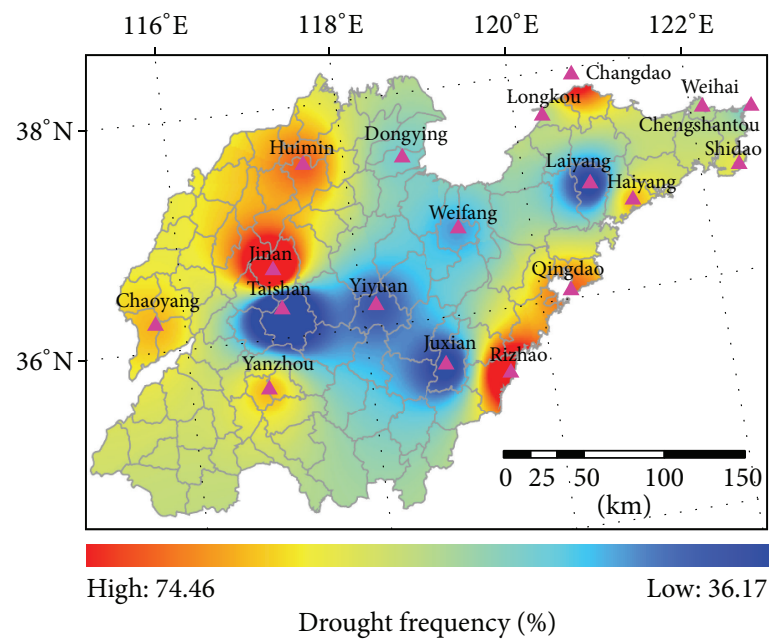

- Meteorological station

(e)

FIGURE 2: Spatial distribution of annual (a), spring (b), summer (c), autumn (d), and winter (e) drought frequency in Shandong province. 


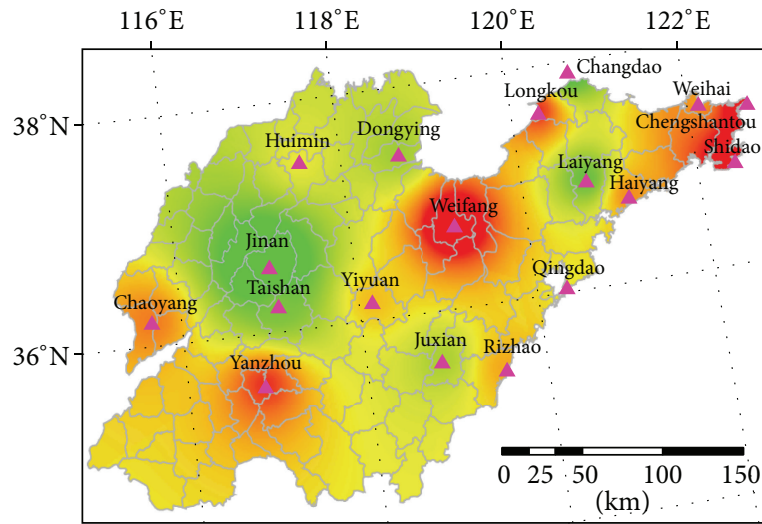

High: 0.87

Climate trend coefficient

- Meteorological station

(a)

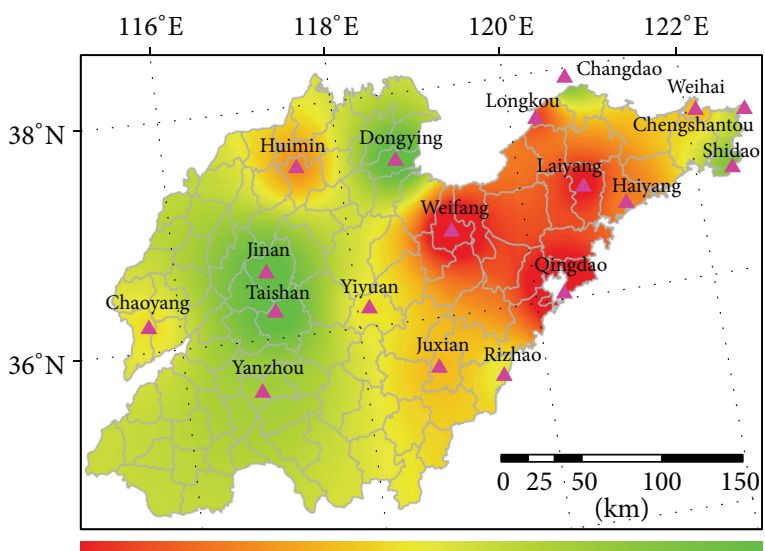

High: 0.67

Climate trend coefficient

- Meteorological station

(c)

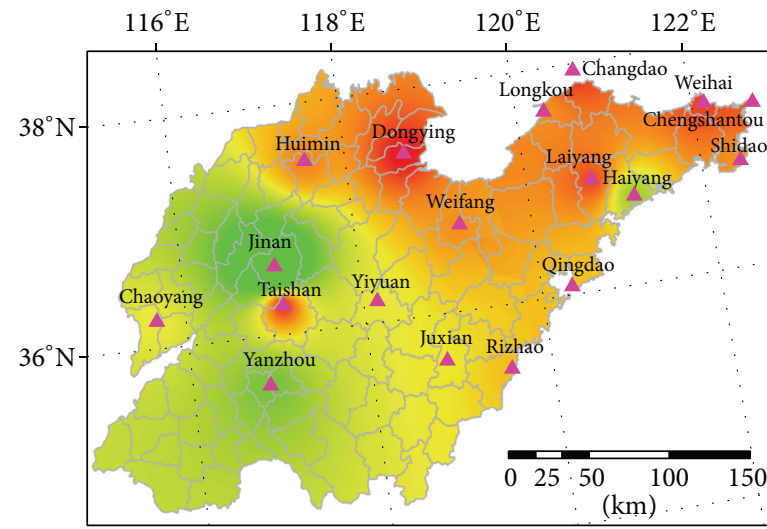

High: 0.78

Climate trend coefficient

Low: -0.71

- Meteorological station

(b)

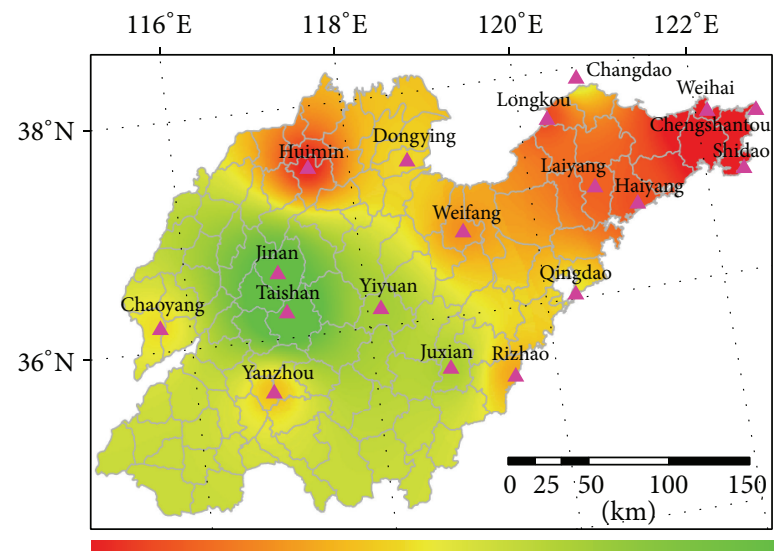

High: 0.85

Climate trend coefficient

Low: -0.71

- Meteorological station

(d)

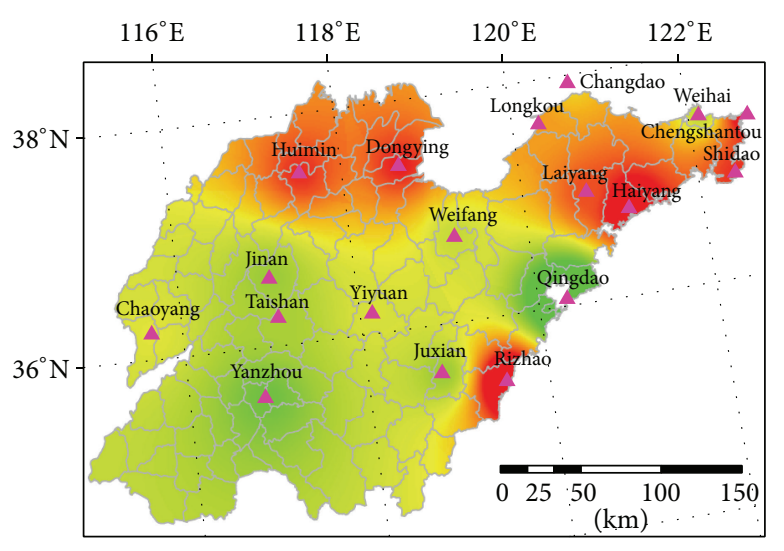

High: 0.99

Climate trend coefficient

Low: -0.91

- Meteorological station

(e)

FIGURE 3: Spatial distribution of annual (a), spring (b), summer (c), autumn (d), and winter (e) climate trend coefficient of drought frequency in Shandong province. 


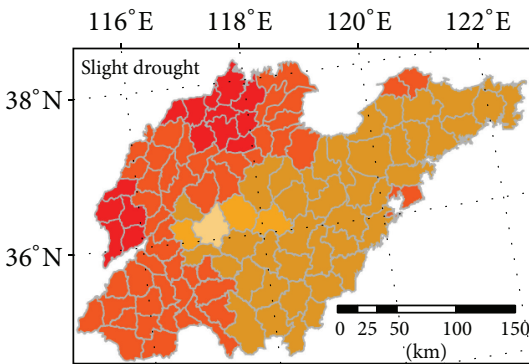

Drought days (d/a)

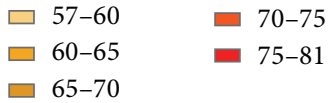

(a)

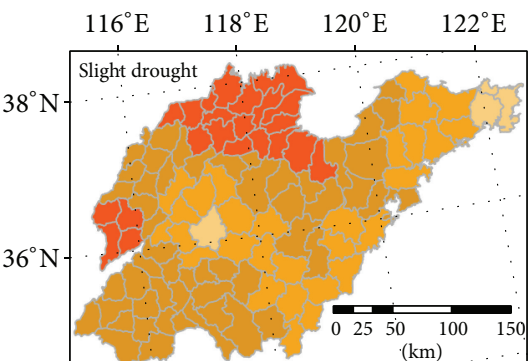

Drought days (d/a)

$\square$ 16-18 $\square$ 20-22

$\square$ 18-20

- 22-25

(d)

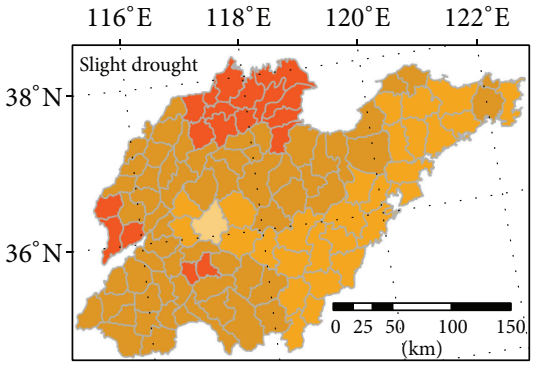

Drought days (d/a)

$\square$ 10-12 $\square$ 14-16

$\square 12-14$

- 16-17

(g)

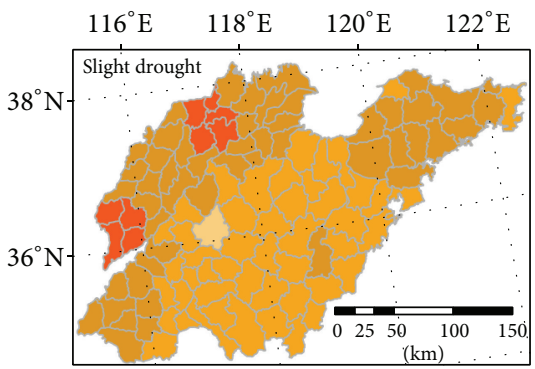

Drought days (d/a)

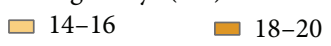

$\square 16-18$

-20-22

(j)

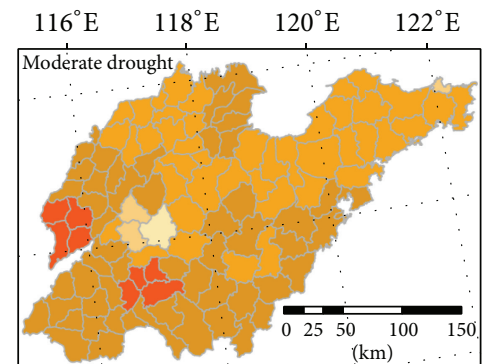

Drought days (d/a)

$\square$ 32-35

- 43-46

$\square$ 35-40

- 46-49

(b)

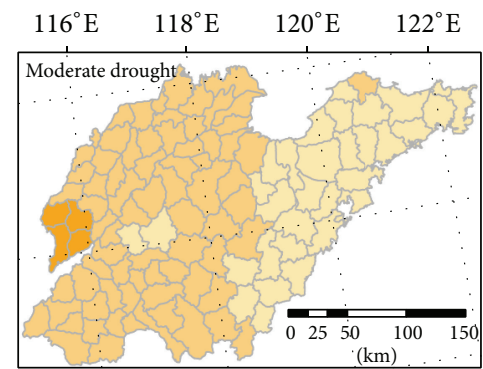

Drought days (d/a)

$\square$ 11-13

$\square$ 15-16

$\square$ 13-15

(e)

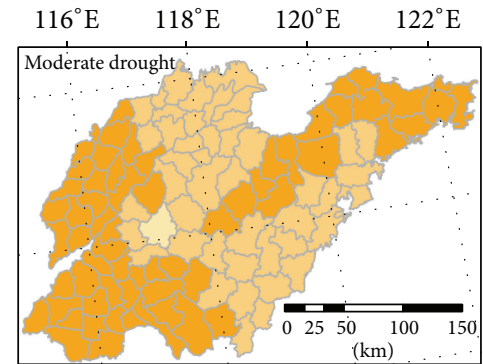

Drought days (d/a)

$\square$ 5-7

$\square$ 9-11

$\square$ 7-9

(h)

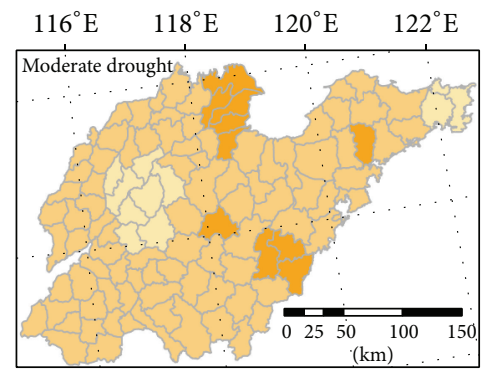

Drought days (d/a)

\section{$\square$ 9-11}

$\square$ 13-15

$\square$ 11-13

(k)

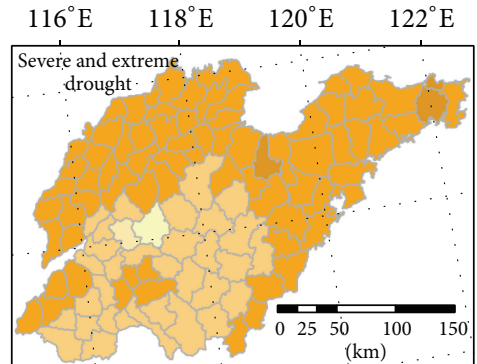

Drought days (d/a)

$\square$ 11-13 $\square$ 17-20

$\square$ 13-15 $20-23$

$\square$ 15-17

(c)

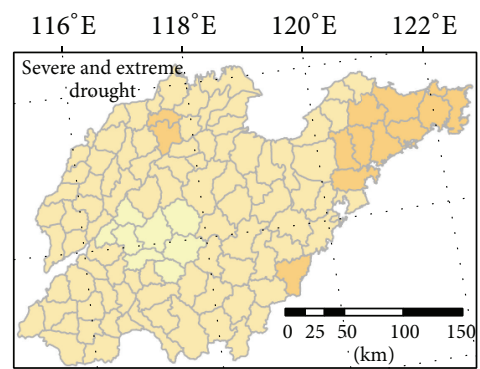

Drought days (d/a)

$\square$ 4-6 $\square$ 7-9

$\square$ 6-7

(f)

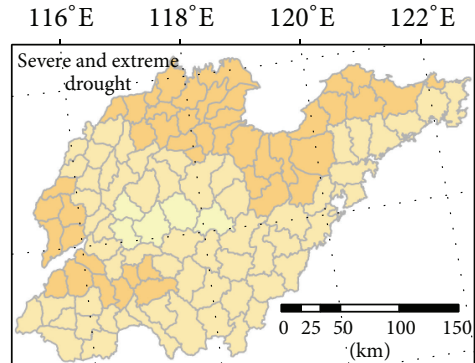

Drought days (d/a)

$\square$ 3-4 $\square$ 5-7

$\square$ 4-5

(i)

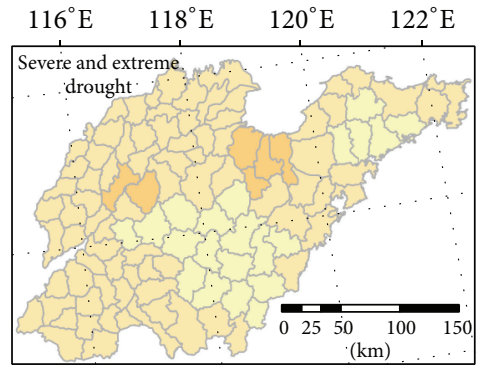

Drought days (d/a)

$\square$ 3-4

$\square$ 5-6

$\square$ 4-5

(l)

Figure 4: Continued. 


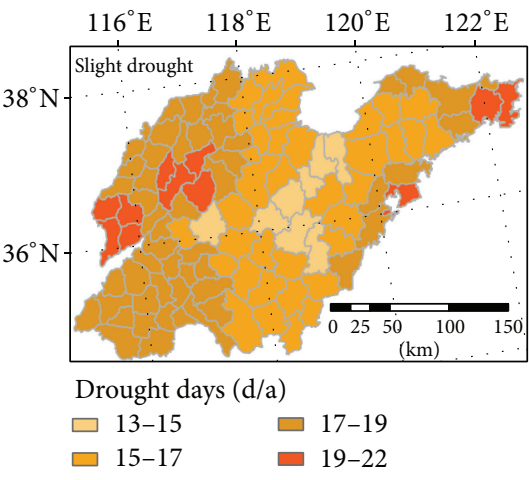

(m)

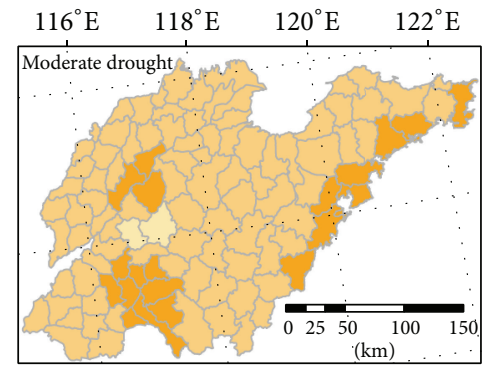

Drought days (d/a)

$\square$ 4-7 $\square 9-11$

$\square$ 7-9

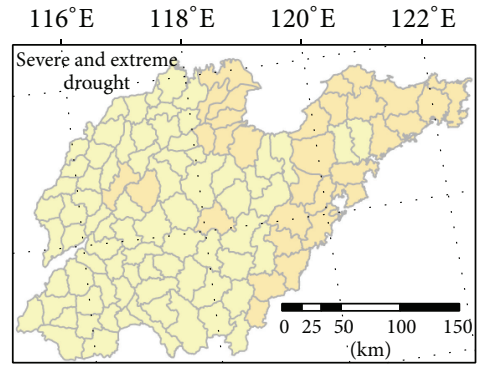

Drought days (d/a)

$\square 0-2$

$\square 2-4$

(n)

(o)

Figure 4: Spatial patterns of annual $((\mathrm{a}) \sim(\mathrm{c}))$, spring $((\mathrm{d}) \sim(\mathrm{f}))$, summer $((\mathrm{g}) \sim(\mathrm{i}))$, autumn $((\mathrm{j}) \sim(\mathrm{l}))$, and winter $((\mathrm{m}) \sim(\mathrm{o}))$ different drought grades in Shandong province.

In winter, the annual drought days for different grades were 14 22 d (Figure 4(m)), 9 15 d (Figure 4(n)), and 3 6 d (Figure 4(o)), respectively. The northwest, southwest, and eastern coastal areas were prone to slight drought in winter; however, the moderate drought days distributed evenly in the study area, ranging between 7 and $9 \mathrm{~d}$ generally. Besides, the severe and extreme drought in winter was the least severity in four seasons, having only 0 to 2 drought days in most parts of the province.

To sum up, each grade of drought that lasts a relatively long time has occurred in Shandong province from 1962 to 2008. And the slight drought was generally observed in the northwest and southwest both for annual and seasonal, but the other grades of drought were observed in different areas for different timescales.

4.3. Temporal Characteristics of Drought Coverage Area. The temporal sequence of PDCA in Shandong province from 1962 to 2008 is shown in Figure 5. The annual average PDCA was $75 \%$, and the annual large-area drought was observed in 14 a which was evenly distributed in the 1980s and 1990s. Relatively, the probabilities of drought extent are zero in 1964 and 2003, revealing that there were no drought events at time scale of year in these two years in Shandong province. For each season, the annual probability of an area affected by a drought in spring, summer, autumn, and winter was $72 \%$, $61 \%, 65 \%$, and $58 \%$, respectively. There were 21 a of large-area drought which was mainly distributed in the 1980s, 1990s, and early 21 s century in spring, and 9 a, 12 a, and 11 a of large-area drought in summer, autumn, and winter whereas almost all of these years concentrated in the 1980s and 1990s. Meanwhile, the nondrought years for every season were relatively few over the past nearly 50 years, only $4 \mathrm{a}$ in spring, $3 \mathrm{a}$ in summer, and $2 \mathrm{a}$ both in autumn and winter. In summary, the largearea drought at annual and seasonal time scales in Shandong province mostly occurred in the 1980s and 1990s.

Moreover, time-continuous large-area drought events have been observed in a few years in Shandong province; in specific, transseasonal large-area droughts that covers spring, summer, and autumn occurred in 1981, 1988, and 2001, respectively. Autumn-winter continuous large-area droughts

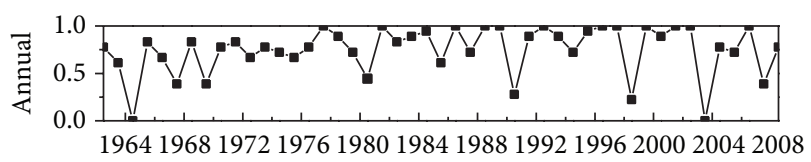

(a)

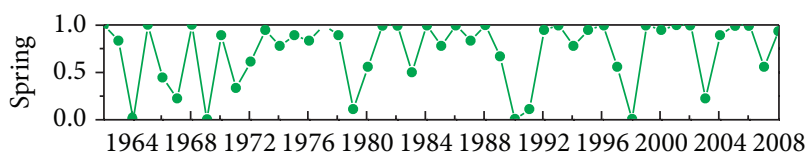

(b)

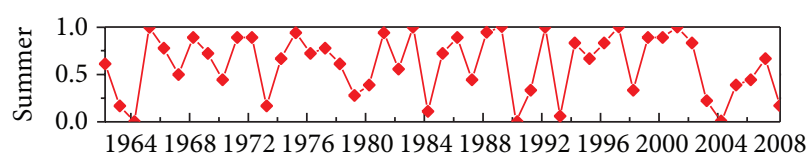

(c)

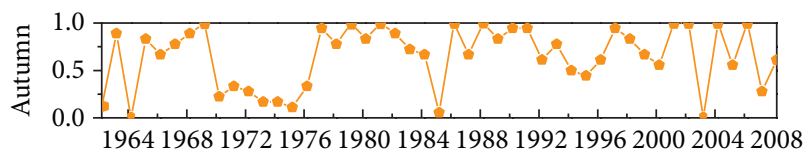

(d)

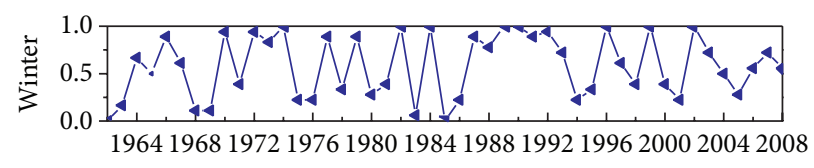

(e)

FIGURE 5: Annual, spring, summer, autumn, and winter probability of drought coverage area in Shandong province.

happened in 1990 and 2002, respectively. Serious springsummer large-area drought occurred in 1992 and summerautumn large-area drought occurred in 1997, respectively. It can be seen that time-continuous large-area droughts mainly took place after the 1970s in Shandong province, revealing that time-continuous droughts were steadily increasing with time during the study period. However, it is also found that the linear changing tendencies were not obvious in the annual and seasonal PDCA in Shandong province by carrying out 
the $F$ significance test with the confidence level of $\alpha=0.01$ and $\alpha=0.05$.

4.4. Temporal Characteristics of Drought Duration. As is shown in Figure 6, the annual and seasonal drought durations in Shandong province were both fluctuated significantly from 1962 to 2008 . The annual drought duration was $153 \mathrm{~d}$, with the longest drought duration of $291 \mathrm{~d}$ in 1999 and the shortest drought duration of $8 \mathrm{~d}$ in 1964 . There were 15 years that the annual drought duration of which was more than 183 days (half of the total days of a year), and furthermore, these years were mainly in the 1980s and 1990s. On seasonal, the annual drought durations in summer and winter were both $34 \mathrm{~d}$ and in spring and autumn were $45 \mathrm{~d}$ and $39 \mathrm{~d}$, respectively. Over the past nearly 50 years, there were $24 \mathrm{a}, 12 \mathrm{a}, 16 \mathrm{a}$, and $12 \mathrm{a}$ that annual drought duration was more than $46 \mathrm{~d}$ (half of the total days of one season) in spring, summer, autumn, and winter, respectively. The longest annual drought duration for spring, summer, autumn, and winter was $84 \mathrm{~d}$ in 1988, $76 \mathrm{~d}$ in 1992, $78 \mathrm{~d}$ in 2002 , and $89 \mathrm{~d}$ in 1999, respectively; correspondingly, the shortest annual drought duration in spring and summer was $0 \mathrm{~d}$ in 1990, while in autumn and winter was $0 \mathrm{~d}$ in 1964 and 2003 and $1 \mathrm{~d}$ in 1964, respectively.

It reveals that the periodic variation of the annual and seasonal interdecadal drought duration was roughly similar, showing a cycle of $10 \mathrm{a}$ approximately (Table 2). But the linear changing tendencies of drought time duration in Shandong province from 1962 to 2008 were insignificant through executing the $F$ significance test with the confidence level of $\alpha=0.01$ and $\alpha=0.05$.

4.5. Temporal Characteristics of Drought Intensity. Over the past nearly 50 years, the annual drought intensity, which is referred to the arithmetic mean of the sum of all the days of CI value that are all above slight drought level for total meteorological stations for each year in Shandong province, showed a fluctuation tendency (Figure 7). The minimum CI value which indicates the strongest drought intensity was -369.93 and appeared in 1988, followed by -333.56 in 1999 , and the maximum CI value conversely implying the lightest drought intensity was -15.22 in 1964 . There are $19 \mathrm{a}$ that annual drought intensity was above the mean intensity for total years from 1962 to 2008, and those years were mainly in the 1980s, 1990s, and early 21 s century. However, the linear tendency of annual drought intensity has not passed the $F$ significance test with the confidence level of $\alpha=0.01$ and $\alpha=$ 0.05 , revealing that the variation tendency of annual drought intensity was much complicated in Shandong province.

The linear tendencies of PDCA and drought duration for annual and seasonal and annual drought intensity were all insignificant; however, it is still obvious that the temporal drought parameters were salient in the 1980s and 1990s than in any other decades, which gives an evidence of the highlighting drought extent and influence in these two decades in Shandong province. In addition, the three temporal drought parameters were all the palest in 1964, demonstrating that the drought was lightest in this year in Shandong province. Moreover, taking into account the annual drought duration and intensity, it is found that the drought duration in 1999

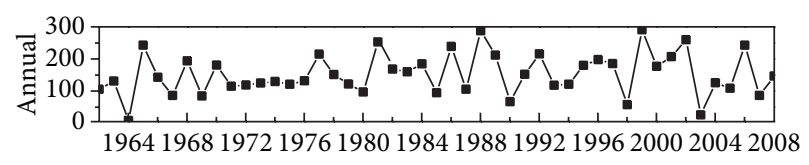

(a)

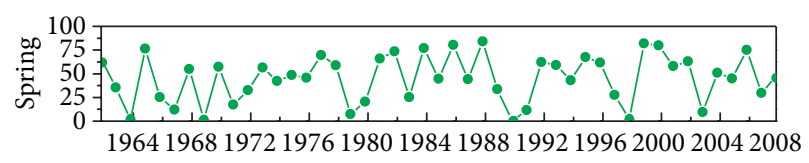

(b)

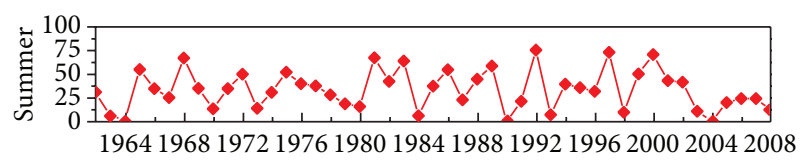

(c)

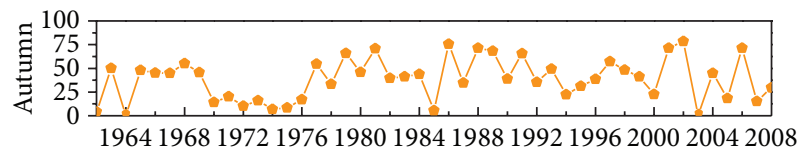

(d)

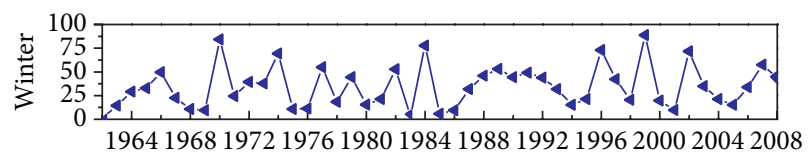

(e)

Figure 6: Annual, spring, summer, autumn, and winter drought duration in Shandong province.

TABLE 2: Annual and seasonal interdecadal drought duration (d).

\begin{tabular}{lccccc}
\hline \multirow{2}{*}{ Inter-decadal } & \multicolumn{5}{c}{ Timescales } \\
& Year & Spring & Summer & Autumn & Winter \\
\hline $60 \mathrm{~s}$ & 124 & 34 & 32 & 37 & 21 \\
$70 \mathrm{~s}$ & 141 & 44 & 32 & 25 & 39 \\
$80 \mathrm{~s}$ & 180 & 55 & 42 & 50 & 32 \\
$90 \mathrm{~s}$ & 159 & 42 & 35 & 43 & 43 \\
Early 21 s & 153 & 51 & 32 & 39 & 34 \\
\hline
\end{tabular}

was $291 \mathrm{~d}$ which was longer than $288 \mathrm{~d}$ in 1988 , whereas the annual drought intensity was -333.56 in 1999 , which was lower than -369.93 in 1988, indicating that the drought cumulative effects in 1988 were more significant than in 1999. In general, the three temporal parameters of drought, namely, PDCA, drought duration, and drought intensity, effectively depict the drought from different aspects and all of them are of great importance to the evaluation of the meteorological drought.

\section{Conclusion and Discussion}

Owing to various factors such as global warming, abnormity of East Asia monsoon wind, and local precipitation decreasing, the drought hazard in Shandong province is becoming more and more serious. Therefore, on the basis 


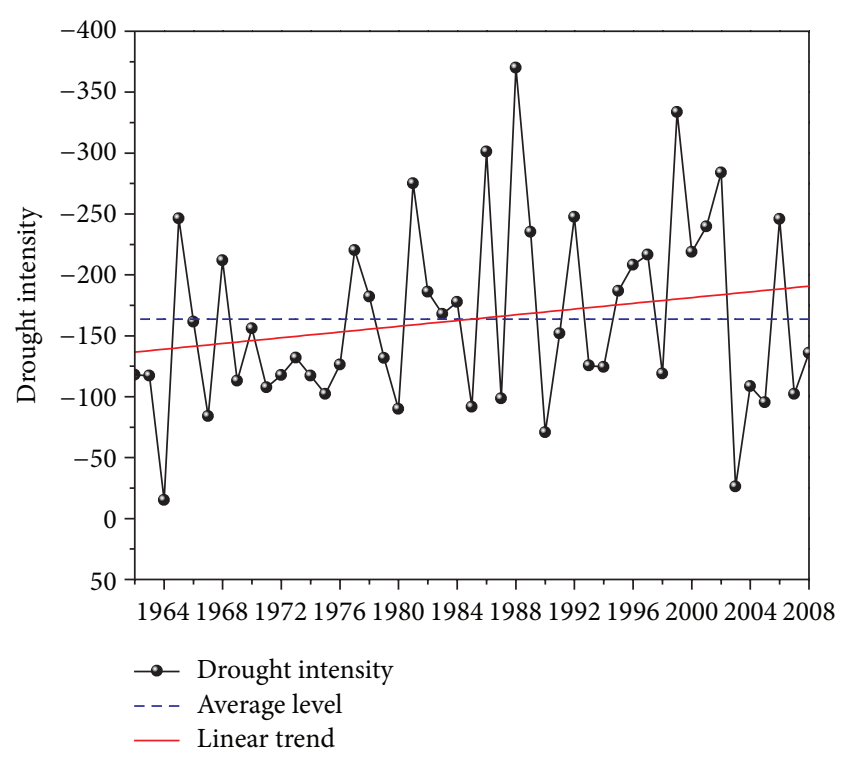

FIgURE 7: The annual drought intensity in Shandong province.

of drought analysis by adopting and calculating the CI for 18 meteorological stations, we comprehensively evaluated the spatial-temporal characteristics of meteorological drought in Shandong province from 1962 to 2008 . Main conclusions are as follows.

The frequency of meteorological drought was generally high in Shandong province, and high-frequency regions are mainly concentrated in the southwest and north areas whereas low-frequency regions are generally centered in the central and southeast. The spatial pattern of drought frequency is closely related to the distribution of precipitation which decreases from southeast to northwest and temperature which increases from northeast to southwest.

The seasonal drought frequency followed such an order of spring $>$ autumn $>$ summer $>$ winter. The precipitation is rare in spring but the evaporation is high due to the land surface warming rapidly, which aggravates the spring drought. In contrast, abundant rain falls in summer and low evaporation in winter owing to low temperature result in relatively low drought frequency in these two seasons.

The slight drought, moderate drought, and severe and extreme drought were all observed in Shandong province from 1962 to 2008 . And the slight drought generally occurred in the northwest and southwest, but drought of other grades was observed in different areas at different timescales. Additionally, various drought grades were longest in spring but shortest in winter which was consistent with the statistics of the calculated drought parameters and, therefore, further revealed that the spring drought was much more serious than that in the other three seasons.

With respect to the temporal trend of drought frequency, it demonstrated that regions including north, south, and Jiaodong peninsula were all suffering an ascend drought over the past nearly 50 years, but the upward trend in other regions was much evident. Besides, temporal trends of multiple drought parameters including PDCA, drought duration, and drought intensity all indicated that the drought extent and influence were very severe in the 1980s and 1990s but much mild in 1964; the time-continuous largearea droughts mainly occurred after the 1970s, and the interdecadal drought duration at annual and seasonal scales both showed a fluctuation tendency of 10 a periodic cycle approximately.

In brief, this study proves that Shandong province is a sensitive area to global climate change from the perspective of meteorological drought occurrence. What is more, the much complicated spatial-temporal characteristics of meteorological drought in Shandong province detected by this study do confirm that the regional response to climate change exhibits very significant spatial-temporal differences. The findings summed up above will in turn give us essential knowledge and guidelines on adaptation and mitigation options to address climate change. In specific, in Shandong province, critical works to be carried out are as follows: (1) to conduct more wide and more extensive monitoring and observations in terms of climate change and drought hazards, and to carry out more intensive scientific researches that focus on the dynamics of meteorological drought; (2) to strengthen drought risk management practices in the public sector, especially to choose and enact defense-oriented strategies, and to develop drought emergency plans and measures at the same time; (3) to maintain and make use of the ecosystem functions and services in terms of drought risk defense and water conversation by protecting and restoring ecosystems in ecocritical areas and drought prone areas; (4) to investigate, choose, develop, and promote effective measures of drought defense and prevention among agricultural, industrial, and energy sectors and people's lives, such as dry farming and water-saving agriculture, green-water utilization technologies, industrial water-saving technologies, and domestic water conservation technologies; (5) to promote public education and to motivate public participation with respect to drought defense and prevention, and so on.

\section{Conflict of Interests}

The authors declare that there is no conflict of interests regarding the publication of this paper.

\section{Acknowledgments}

This research was financially supported by the CAS Strategic Priority Research Program (Grant no. XDA05130703), the Key Research Program of the Chinese Academy of Sciences (Grant no. KZZD-EW-14), and the Research Program of Shandong Association for Science \& Technology (Grant no. 20130202). The authors appreciate the reviewers and editors for the positive remarks and insightful comments as well as suggestions.

\section{References}

[1] R. Alley, T. Berntsen, N. L. Bindoff et al., Climate Change 2007: The Physical Science Basis, Summary for Policy Makers, Intergovernmental Panel on Climate Change, 2007. 
[2] A. K. Mishra and V. P. Singh, "A review of drought concepts," Journal of Hydrology, vol. 391, no. 1-2, pp. 202-216, 2010.

[3] N. Zeng, "Drought in the Sahel," Science, vol. 302, no. 5647, pp. 999-1000, 2003.

[4] H. Ezzine, A. Bouzuane, and D. Ouazar, "Seasonal comparisons of meteorological and agricultural drought indices in Morocco using open short time-series data," International Journal of Applied Earth Observation and Geoinformation, vol. 26, pp. 3648, 2014.

[5] S. Agrawala, M. Barlow, H. Cullen, and B. Lyon, The Drought and Humanitarian Crisis in Central and Southwest Asia: A Climate Perspective, International Research Institute (IRI) for Climate and Society, 2001.

[6] X. K. Zou, P. M. Zhai, and Q. Zhang, "Variations in droughts over China: 1951-2003," Geophysical Research Letters, vol. 32, no. 4, Article ID L04707, 2005.

[7] S. Demuth and K. Stahl, Assessment of the Regional Impact of Droughts in Europe. Final Report to the European Union, Institute of Hydrology, University of Freiburg, Freiburg, Germany, 2001.

[8] B. Lehner, P. Döll, J. Alcamo, T. Henrichs, and F. Kaspar, "Estimating the impact of global change on flood and drought risks in Europe: a continental, integrated analysis," Climatic Change, vol. 75, no. 3, pp. 273-299, 2006.

[9] E. R. Cook, R. Seager, M. A. Cane, and D. W. Stahle, "North American drought: reconstructions, causes, and consequences," Earth-Science Reviews, vol. 81, no. 1-2, pp. 93-134, 2007.

[10] K. E. Logan, N. A. Brunsell, A. R. Jones, and J. J. Feddema, "Assessing spatiotemporal variability of drought in the U.S. central plains," Journal of Arid Environments, vol. 74, no. 2, pp. 247-255, 2010.

[11] A. Wang, D. P. Lettenmaier, and J. Sheffield, "Soil moisture drought in China, 1950-2006," Journal of Climate, vol. 24, no. 13, pp. 3257-3271, 2011.

[12] E. Lu, Y. Luo, R. Zhang, Q. Wu, and L. Liu, "Regional atmospheric anomalies responsible for the 2009-2010 severe drought in China," Journal of Geophysical Research D: Atmospheres, vol. 116, no. 21, Article ID D21114, 2011.

[13] Q. Zhang, Drought and Its Impacts, China Climate Impact Assessment, China Meteorol Press, Beijing, China, 2003.

[14] D. Mihajlović, "Monitoring the 2003-2004 meteorological drought over Pannonian part of Croatia," International Journal of Climatology, vol. 26, no. 15, pp. 2213-2225, 2006.

[15] T. B. McKee, N. J. Doesken, and J. Kleist, "The relationship of drought frequency and duration to time scales," in Proceedings of the 8th Conference on Applied Climatology, American Meteorological Society, Anaheim, Calif, USA, January 1993.

[16] T. B. McKee, N. J. Doesken, and J. Kleist, "Drought monitoring with multiple time scales," in Proceedings of the 9th Conference on Applied Climatology, pp. 233-236, American Meteorological Society, Dallas, Tex, USA, January 1995.

[17] C. S. Rim, "The implications of geography and climate on drought trend," International Journal of Climatology, vol. 33, no. 13, pp. 2799-2815, 2013.

[18] W. C. Palmer, "Meteorological drought," Research Paper 45, US Department of Commerce, Weather Bureau, 1965.

[19] A. Dai, K. E. Trenberth, and T. Qian, "A global dataset of Palmer Drought Severity Index for 1870-2002: relationship with soil moisture and effects of surface warming," Journal of Hydrometeorology, vol. 5, no. 6, pp. 1117-1130, 2004.
[20] F. N. Kogan, "Global Drought Watch from Space," Bulletin of the American Meteorological Society, vol. 78, no. 4, pp. 621-636, 1997.

[21] S. M. Quiring and S. Ganesh, "Evaluating the utility of the Vegetation Condition Index (VCI) for monitoring meteorological drought in Texas," Agricultural and Forest Meteorology, vol. 150, no. 3, pp. 330-339, 2010.

[22] Q. Zhang, X. K. Zou, and F. J. Xiao, Meteorological Drought Level GB/T20481-2006, Standards Press, Beijing, China, 2006.

[23] C. H. Zhao, X. Z. Deng, Y. W. Yuan, H. Yan, and H. Liang, "Prediction of drought risk based on the WRF model in Yuannan province of China," Advances in Meteorology, vol. 2013, Article ID 295856, 9 pages, 2013.

[24] X. K. Zou, G. Y. Ren, and Q. Zhang, "Droughts variations in China based on a compound index of meteorological drought," Climatic and Environmental Research, vol. 15, no. 4, pp. 371-378, 2010 (Chinese).

[25] T. Zhang, B. Zhang, Y. Wang, X. Liu, M. An, and J. Zhang, "Drought characteristics in the Shiyang River Basin during the recent 50 years based on a composite index," Acta Ecologica Sinica, vol. 33, no. 3, pp. 975-984, 2013 (Chinese).

[26] Y. Bao, C. Meng, S. Shen, X. Qiu, P. Gao, and C. Liu, “Temporal and spatial patterns of droughts for recent 50 years in Jiangsu based on meteorological drought composite index," Acta Geographica Sinica, vol. 66, no. 5, pp. 599-608, 2011 (Chinese).

[27] D. Q. Xue, J. G. Wang, X. T. Wang, and D. L. Gong, "Characteristic analysis of change into drought in Shandong Province," Journal of Natural Disasters, vol. 16, no. 3, pp. 60-65, 2007 (Chinese).

[28] Z. Gao, W. Gao, and N. B. Chang, "Integrating temperature vegetation dryness index (TVDI) and regional water stress index (RWSI) for drought assessment with the aid of LANDSAT TM/ETM+images," International Journal of Applied Earth Observation and Geoinformation, vol. 13, no. 3, pp. 495-503, 2011.

[29] H. H. Jiang, "Variance features and correlativity analysis of drought disasters in Shandong Province," Journal of Catastrophology, vol. 15, no. 3, pp. 51-55, 2000 (Chinese).

[30] L. Du, Q. Tian, Y. Huang, and J. Liu, "Drought monitoring based on TRMM data and its reliability validation in Shandong province," Transactions of the Chinese Society of Agricultural Engineering, vol. 28, no. 2, pp. 121-126, 2012 (Chinese).

[31] L. Du, Q. Tian, T. Yu et al., "A comprehensive drought monitoring method integrating MODIS and TRMM data," International Journal of Applied Earth Observation and Geoinformation, vol. 23, no. 1, pp. 245-253, 2013.

[32] B. Gao, J. Z. Fan, Y. G. Jing et al., "Variation characteristics of sunshine hours and its reason analysis over loess plateau of Shaanxi," Meteorological and Environmental Research, vol. 2, no. 10, pp. 44-49, 2011. 

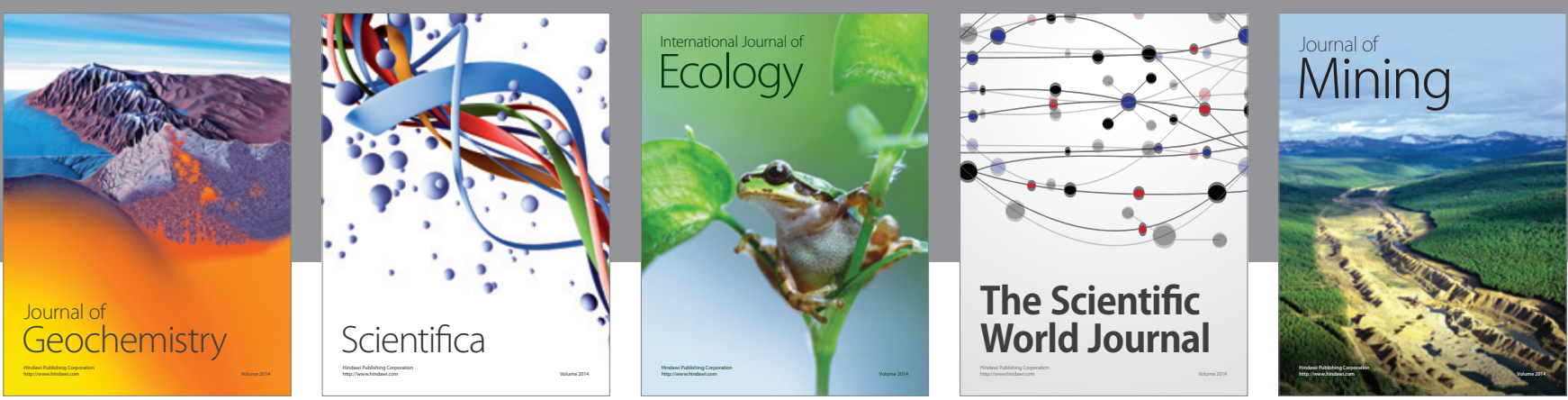

The Scientific World Journal
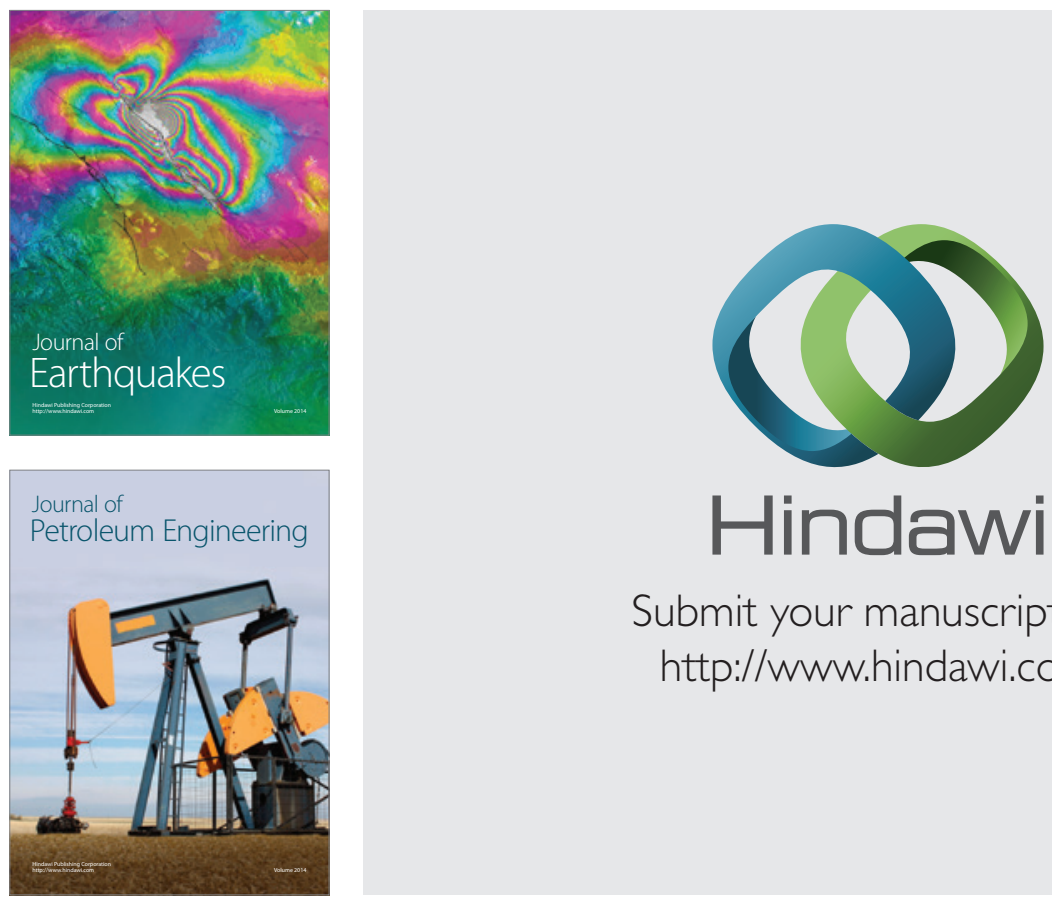

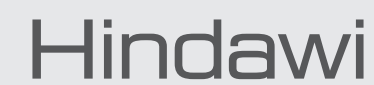

Submit your manuscripts at

http://www.hindawi.com
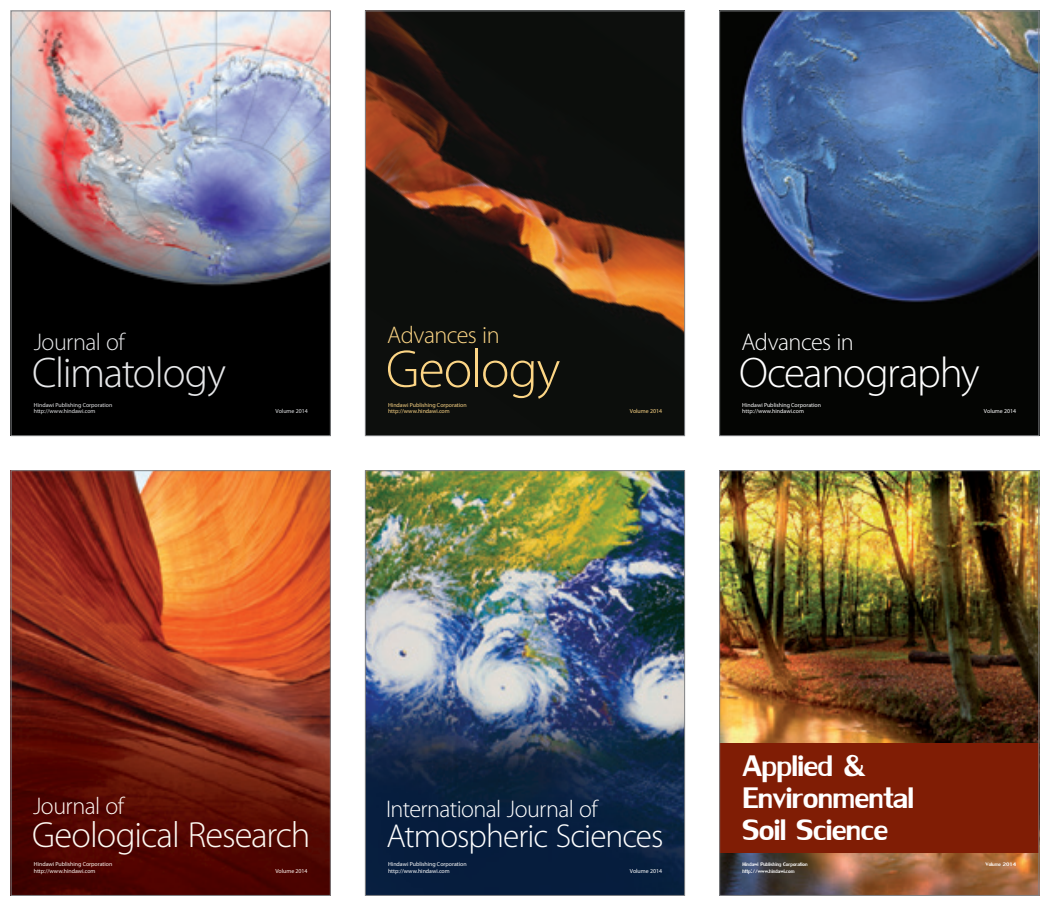
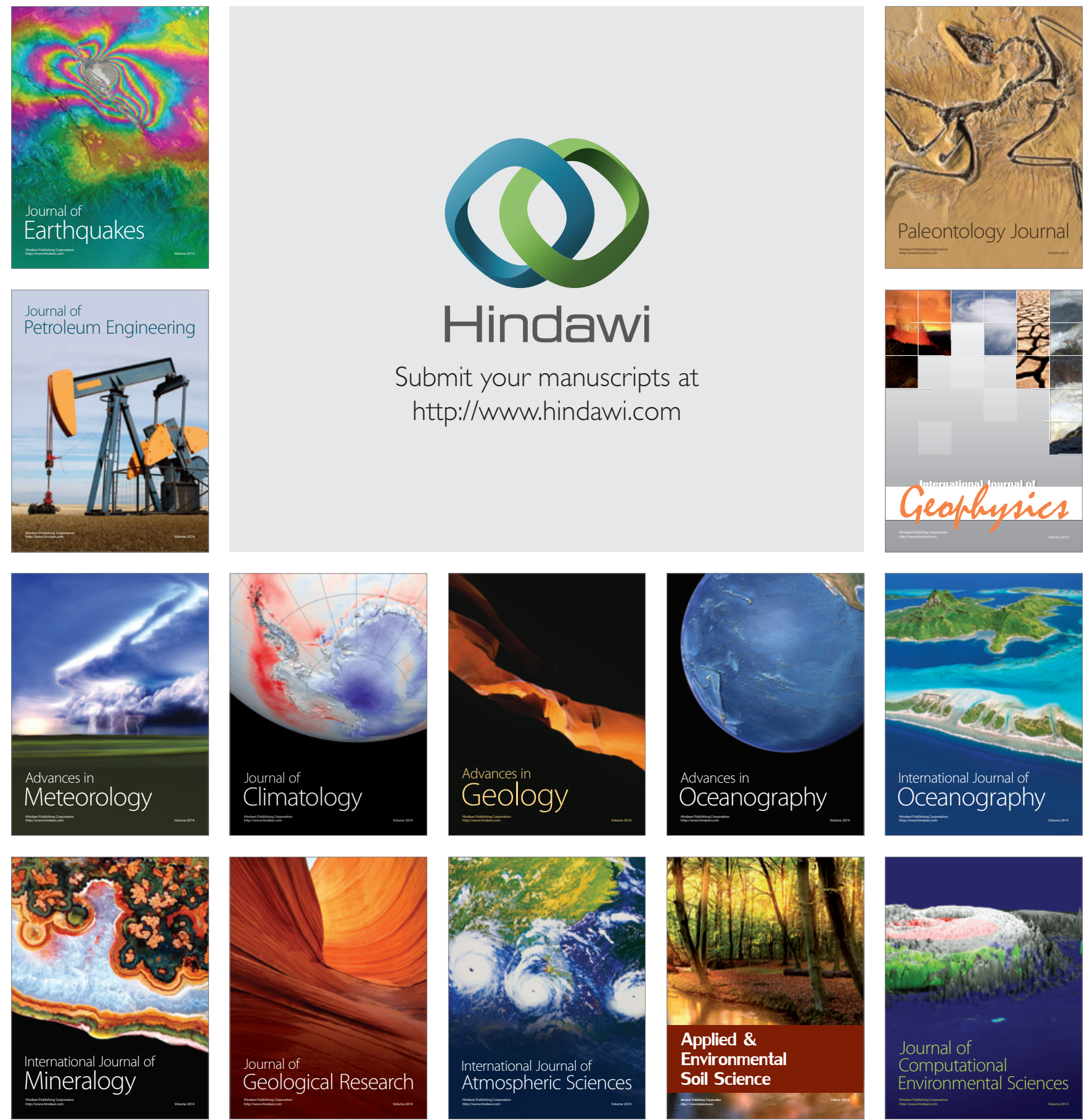